\title{
Kecerdasan Budaya dan Gaya Belajar Mahasiswa yang Merantau di DKI Jakarta
}

\section{Culture Intelligence and Learning Style among Migrating Student in Dki Jakarta}

\author{
Arif Triman ${ }^{1}$, Abdillah $^{1}$ \\ ${ }^{1}$ Fakultas Psikologi Universitas YARSI \\ E-mail: arif.triman@yarsi.ac.id
}

KEYWORDS cultural intelligence, grasha learning style, students

ABSTRACT Indonesia is a developing country with an uneven educational infrastructure development. It impacts the number of students from rural areas to big cities to get a decent education. Many of those students are experiencing difficulties when entering a new culture, thus disrupting their adjustment, especially in learning styles. The purpose of this study is to investigate any possible correlation between cultural intelligence and Grasha learning style. Participants in this study were 121 students in DKI Jakarta. Cultural Intelligence Scale and Grasha-Riecment Learning Scale Style were used as instruments in this study. Using regression analysis, it was found that 2 of 6 learning style (Collaborative learning style and Independent learning style) were found to have significant role in Cultural Intelligents.

\section{PENDAHULUAN}

Indonesia mempunyai wilayah kepulauan yang sangat luas serta sumber daya alam dan manusia yang melimpah. Namun, luasnya wilayah Indonesia tidak disertai dengan pembangunan yang merata. Sebanyak $50 \%$ pembangunan di Indonesia berpusat di pulau Jawa (Gusman, 2015). Hal tersebut berdampak pada terjadinya perbedaan mutu pendidikan antar daerah di Indonesia. Kurniawan (2013) menjelaskan bahwa keterbatasan akses pendidikan di daerah menyebabkan terjadinya proses urbanisasi ke daerah yang memiliki fasilitas pendidikan lebih baik, terutama pada kota besar seperti di DKI Jakarta.

Individu yang melakukan urbanisasi untuk menempuh pendidikan tinggi disebut sebagai mahasiswa perantau. Mahasiswa perantau adalah sekelompok individu yang berada pada tahapan usia dewasa awal yang mengambil keputusan untuk menuntut ilmu di luar daerah asalnya dalam jangka waktu tertentu, atas kemaunnya sendiri. Adanya proses urbanisasi tentunya membuat para mahasiswa perantau membutuhkan penyesuaian diri khusus terkait dengan perbedaan budaya yang dihadapi di tempat baru. Contoh kasus yang terjadi di Yogyakarta, dimana banyak mahasiswa perantau di Yogyakarta yang mengalami culture shock baik di kampus, lingkungan tempat tinggal dan lainnya (Devinta, 2015). Menurut Primasari (2014) mahasiswa yang tidak mempunyai keberanian akan sulit beradaptasi dan bersosialisasi dengan lingkungan disekitar mereka, terlebih jika mahasiswa tersebut harus beradaptasi dengan budaya yang $180^{\circ}$ berbeda dengan kampung halamannya. Oleh karena itu, untuk mengatasi kemungkinan terjadinya culture shock, mahasiswa perantau perlu memiliki kemampuan beradaptasi dengan budaya baru yang baik, di mana kemampuan 
tersebut dalam istilah psikologi disebut sebagai kecerdasan budaya. Menurut Early dan Ang (dalam Chen, 2015) individu yang mempunyai kecerdasan budaya tinggi mampu mengatasi adanya culture shock pada dirinya.

Kecerdasan budaya didefinisikan sebagai suatu kemampuan yang dimiliki oleh individu untuk menyesuaikan diri secara efektif dengan lingkungan budaya yang baru atau keragaman budaya yang berbeda dengan daerah tempat tinggal asalnya (Early \& Ang, 2003). Kecerdasan budaya, akan membantu mahasiswa perantau untuk beradaptasi dengan budaya baru (Chen, 2015). Seseorang dengan kemampuan kecerdasan budaya yang tinggi, memiliki kemampuan yang baik untuk mempelajari lingkungan budaya yang baru dan menikmati berada di lingkungan yang baru. Namun, pada kenyataannya masih terdapat mahasiswa perantau yang memiliki kemampuan kecerdasan budaya yang kurang baik, sehingga mereka tidak mampu mengatasi permasalahan dan tekanan yang berkaitan dengan perbedaan di sekelilingnya. Hasil penelitian yang dilakukan oleh Primasari (2014), menunjukkan bahwa masih banyak mahasiswa perantau yang mengalami kecemasan saat berinteraksi dengan orang lain karena merasa adanya perbedaan budaya. Primasari (2014) menambahkan bahwa hal tersebut terjadi karena kurangnya pengetahuan dan informasi yang dimiliki oleh mahasiswa perantau mengenai budaya di lingkungan barunya.

Kecerdasan budaya merupakan suatu kompetensi yang bisa dipelajari oleh seseorang melalui kesadaran akan budaya disekitarnya (Sutherland, Edgar, Duncan \& Caledonian, 2015). Early dan Ang (2003) turut menjelaskan bahwa kecerdasan budaya bukanlah suatu karakteristik bawaan seseorang, tetapi kecerdasan budaya merupakan suatu kemampuan yang dapat dipelajari melalui pengalaman ketika berada di budaya yang berbeda. Banyak hal yang mempengaruhi proses pembelajaran kecerdasan budaya yang dimiliki seseorang, seperti lamanya seseorang berada di budaya yang berbeda, gaya belajar yang dimiliki oleh orang tersebut (Li, Mobley, \& Kelly, 2013), dan juga kemampuan sosial seseorang (Keyvanara, Yarmohammadian, \& Soltani, 2014).

Proses penyerapan informasi yang dimiliki seseorang untuk mempelajari budaya baru tentunya dipengaruhi oleh gaya belajarnya (Papilaya \& Huliselan, 2016). Dengan mengetahui gaya belajar individu tersebut, maka tujuan pembelajaran dapat dicapai secara efektif. Gaya belajar yang sesuai merupakan salah satu kunci keberhasilan seseorang dalam belajar. Gaya belajar sendiri didefinisikan sebagai kecenderungan atau cara mahasiswa menyerap dan mengkomunikasikan informasi dengan efektif yang direpresentasikan pada pola bicara, cara belajar, cara mengerjakan tugas, cara merespons orang lain, dan kegiatan lain yang disukai (Nugraheni \& Pangaribuan, 2006). Definisi lain mengenai gaya belajar adalah kebiasaan belajar dimana seseorang merasa paling efisien dan efektif dalam menerima, memproses, menyimpan dan mengeluarkan sesuatu yang dipelajari (Wiyono, Liliasari, Setiawan, \& Paulus, 2012). Gaya belajar sendiri memiliki banyak modelnya. Akan tetapi, adanya faktor budaya yang menuntut individu berinteraksi dengan lingkungan sekitar membuat gaya belajar Grasha sangat sesuai digunakan untuk melihat proses pembelajaran individu (Gunawan, 2004).

Penelitian in bertujuan untuk melihat keterkaitan antara gaya belajar yang dikemukakan oleh Grasha dengan kecerdasan budaya. Oleh karena itu, gaya belajar Grasha akan membantu meningkatkan kecerdasan budaya yang dimiliki seseorang. Menurut Grasha dalam Syah (2014), gaya belajar terbagi menjadi 6, yaitu independent learning style dimana seseorang belajar untuk diri sendiri dan yakin akan kemampuanya sendiri, avoidant learning style dimana seseorang 
tidak antusias dalam melakukan pembelajaran dan cendrung menghindar, collaborative learning style dimana seseorang belajar dengan cara berekelompok dan senang bertukar ide antara satu dengan yang lainya, dependent learning style dimana seseorang bergantung pada orang lain dalam melakukan pembelajaran dan biasanya hanya belajar seperlunya saja, competititve learning style dimana seseorang melakukan pembelajaran agar ingin tampil lebih baik dari pada yang lain dan bersaing dengan yang lain agar mendapatkan pengharagaan, dan participant learning style dimana seseorang sering mengambil bagian dalam banyak kegiatan dan selalu bersemangat dalam kegiatan pembelajaran.

\section{METODOLOGI}

Penelitian ini menggunakan pendekatan kuantitatif, karena data-data yang didapat dari penelitian ini merupakan data numerikal (angka) dan akan diolah menggunakan metode statistika, sehingga hasilnya dapat digeneralisasikan. Selain itu, penelitian ini bertujuan untuk menguji hipotesis asosiatif yang dimiliki oleh peneliti, dan melihat hubungan antar variabel yang ada dalam penelitian ini (Azwar, 2012). Penelitian ini menggunakan desain penelitian desain penelitian asosiatif. Peneliti ingin mengetahui keterkaitan antara dua variabel.

Populasi dari penelitian ini adalah individu yang berstatus sebagai mahasiswa perantau yang melakukan kegiatan perkuliahan di daerah DKI Jakarta. Peneliti memilih populasi di daerah Jakarta karena beberapa universitas di Indonesia yang mempunyai kualitas bermutu terdapat di Jakarta. Selain itu jumlah perguruan tinggi/universias di Jakarta terbilang cukup banyak. Sampel dari penelitian ini memilki karakteristik sebagai berikut :

- Laki-laki atau perempuan
- Berstatus sebagai mahasiswa perantau

- Berada di semester 3 hingga 8

- Mahasiswa yang berkuliah di universitas/perguruan tinggi di DKI Jakarta.

Menurut Rosceo (dalam Sugiyono, 2013), ukuran sampel yang layak dalam penelitian adalah antara 30 sampai dengan 500, karena belum diketahui populasi dalam penelitian ini. Pada penelitian ini populasi dari subjek penelitian yang peneliti ambil sangat besar. Maka pada populasi yang besar, peneliti disarankan untuk mengambil sampel sejumlah minimum 100 orang (Alreck \& Settle, 2004).

Penelitian ini menggunakan teknik pengambilan sampel non-probability sampling dimana peluang individu yang berada dalam populasi untuk dipilih menjadi sampel tidak diketahui (Azwar, 2012). Non-probability sampling adalah teknik pengambilan sampel yang tidak memberi peluang/ kesempatan sama bagi setiap unsur atau anggota populasi yang dipilih menjadi sampel (Sugiyono, 2013). Jenis sampling yang peneliti gunakan dalam penelitian ini adalah accidental sampling yaitu teknik penentuan sampel berdasarkan kebetulan, siapa saja yang secara kebetulan/insidental bertemu dengan peneliti dapat digunakan sebagai sampel. (Sugiyono, 2013).

Pada penelitian kali ini peneliti menggunakan alat ukur CQS (Cultural Intelligence Scale) untuk mengukur kecerdasan budaya, dan memiliki 12 aitem. Pada dimensi ICK (Internalized Cultural Knowledge) terdapat 7 aitem. Kemudian untuk dimensi ECF (Effective Cultural Flexibility) terdapat 5 aitem. Sementara itu, untuk mengukur gaya belajar, peneliti menggunakan alat ukur Grasha-Riechment Learrning Scale Style (GRLSS) yang dikembangkan oleh GrashaRiechment. Alat ukur ini memiliki 60 item yang terbagi dari 6 gaya belajar, yaitu : Independent Learning Style, 
Avoidant Learning Style, Collaborative Learning Style, Dependent Learning Style, Competititve Learning Style, dan Participant Learning Style. Nilai reliabilitas alat ukur kecerdasan budaya yang terdiri dari dua dimensi yaitu ICK ( $\alpha$ $=0,802)$ dan ECF $(\alpha=0,624)$. Sedangkan nilai reliabilitas keenam gaya belajar adalah Competitive $\quad(\alpha=0,803)$, Collaborative $\quad(\alpha=0,641), \quad$ Avoidant $(\alpha=0,773), \quad$ Participant $\quad(\alpha=0,773)$, Dependent $(\alpha=0,665)$, dan Independent $(\alpha=0,694)$. Menurut Awar (2012) alat ukur yang memiliki nilai $(\alpha>0.6)$ boleh dikatakan alat ukur yang reliabel dan bisa digunakan untuk penelitian.

\section{ISI}

Sebelum melakukan analisa peran gaya belajar terhadap kecerdasan budaya, maka perlu dilakukan uji korelasi untuk melihat hubungan kedua variabel ini. Berikut hasil uji korelasi gaya belajar dan kecerdasan budaya.

Berdasarkan tabel 2, terlihat hanya dua gaya belajar yaitu gaya belajar Collaborative $(\mathrm{r}=0,041, \mathrm{p}<0,05)$ dan gaya belajar Independen $(\mathrm{r}=0,217$, $\mathrm{p}<0,05)$ yang memiliki hubungan signifikan dengan kecerdasan budaya pada mahasiswa perantau di DKI Jakarta.

Tabel 1. Hubungan Gaya Belajar dengan Kecerdasan Budaya

\begin{tabular}{ccc}
\hline Dimensi & $\boldsymbol{r}$ & $\overline{\text { Sig (2-Tailed) }}$ \\
& & \\
\hline Competitive & 0,041 & 0,659 \\
Collaborative & $\mathbf{0 , 2 8 2}$ & $\mathbf{0 , 0 0 2}$ \\
Avoidant & 0,056 & 0,545 \\
Participant & 0,149 & 0,103 \\
Independent & $\mathbf{0 , 2 1 7}$ & $\mathbf{0 , 0 1 7}$ \\
Dependen & 0,030 & 0,734 \\
\hline
\end{tabular}

Keterangan : Sig. $(p<0,05)$

Berdasarkan syarat uji regresi, hanya variabel yang memiliki hubungan signifikan yang akan digunakan untuk melihat peran variabel bebas terhadap variabel terikat. Dengan demikian, hanya peran gaya belajar Collaborative dan Independen saja yang akan dianalisa untuk melihat perannya terhadap kecerdasan budaya.

Tabel 2. Uji Regresi Gaya Belajar terhadap Kecerdasan Budaya

\begin{tabular}{cccccc}
\hline & $\mathrm{B}$ & & Beta & & $\mathrm{T}$ \\
\cline { 1 - 2 } \cline { 5 - 5 } (Constant) & 17,392 & & & \\
Collaborative & 0,479 & & 0,383 & & 4,594 \\
Independent & 0,226 & & 0,179 & & 2,152 \\
\hline
\end{tabular}

Berdasarkan hasil uji regresi, diketahui bahwa gaya belajar berperan sebesar $20 \%$ terhadap kecerdasan budaya dan sebesar $80 \%$ dipengaruhi oleh faktor lain. Besarnya pengaruh ini terlihat dari nilai $\mathrm{R}=0.447$ dan nilai $\mathrm{R}^{2}=0.200$. Kemudian berdasarkan uji regresi didapatkan konstanta (a) sebesar 17,392 yang menunjukkan bahwa jika tidak ada pengaruh gaya belajar pada mahasiswa perantau maka kecerdasan budaya akan mencapai sebesar 17,392. Berdasarkan hasil uji regresi, didapatkan persamaan regresi Kecerdasan Budaya $=17,392+$ $(0,479) \quad$ Collaborative $+(0,226)$ Independent. Berdasarkan persamaan ini, nilai $(0,479)$ Collaborative merupakan koefisien regresi yang menunjukkan setiap penambahan 1 poin untuk gaya belajar Collaborative maka akan terdapat peningkatan kecerdasan budaya sebesar 0.479 . Sedangkan nilai $(0,226)$ Independent merupakan koefisien regresi yang menunjukkan setiap penambahan 1 poin untuk gaya belajar Independent maka akan terdapat peningkatan kecerdasan budaya sebesar 0.226.

Berdasarkan hasil penelitian ditemukan bahwa terdapat pengaruh yang signifikan antara gaya belajar Collaborative dan Independen terhadap kecerdasan budaya. Persamaan regresi yang didapatkan adalah: Kecerdasan Budaya $=17,392+(0,479)$ Collaborative $+(0,226)$ Independen. Hal ini menunjukkan adanya peranan kedua gaya belajar ini terhadap proses 
pembelajaran dan adaptasi para mahasiswa perantau yang melanjutkan pendidikannya di DKI Jakarta.

Hasil penelitan ini menunjukan terdapat peranan positif gaya belajar Collaborative dengan kecerdasan budaya. Hal ini dapat terjadi karena orang yang mempunyai gaya belajar Collaborative senang bertukar ide dan senang berinteraksi dengan orang lain untuk mendapatkan hal yang baru (Grasha, dalam Chong \& Mahamod, 2014). Grasha juga menambahkan bahwa individu yang cenderung menggunakan gaya belajar ini, senang untuk bekerjasama dan berkoordinasi dengan lingkungan sosialnya. Hal ini tentunya akan memudahkan mahasiswa perantau untuk menyesuaikan diri dengan keberagaman budaya baru yang ia temui. Menurut Bucker, Furrer, dan Lin (2015) orang yang memiliki kecerdasan budaya yang tinggi lebih senang mempelajari hal-hal baru terkait budaya yang baru. Oleh karena itu, gaya belajar Collaborative tentunya akan mendukung peningkatan kecerdasan budaya yang dimiliki oleh para mahasiswa perantau.

Sementara itu, gaya belajar Independent juga menunjukkan peran positif terhadap kecerdasan budaya, Hal ini terjadi karena orang yang mempunyai gaya belajar Independent pada umumnya mau mencari tahu halhal yang baru dengan kemampuan yang ia memiliki (Grasha 2002). Lebih jauh lagi, individu yang memiliki gaya belajar Independent tentunya tidak akan mengalami hambatan untuk meningkatkan pemahamannya terhadap budaya baru, baik dipelajari secara individu maupun bekerjasama dengan teman-temannya. Dengan ciri dan karakteristik seperti ini tentunya memudahkan mahasiswa perantu untuk mengasah lagi kecerdasan budaya yang ia miliki.

\section{PENUTUP}

Berdasarkan hasil penelitian didapatkan bahwa dari keenam gaya belajar yang didasarkan dari teori Grasha (2002), terdapat hubungan yang signifikan antara gaya belajar Collaborative dan Independen dengan kecerdasan budaya. Uji regresi juga memperlihatkan adanya peran yang signifikan dari kedua gaya belajar ini terhadap kecerdasan budaya. Oleh karena itu, dapat disimpulkan mahasiswa perantau yang ingin mengasah kecerdasan budaya saat merantau, lebih efektif menggunakan gaya belajar Collaborative dan Independent. Kedua ciri dan karakteristik gaya belajar ini sangat mendukung pemahaman dan penyerapan informasi seorang mahasiswa akan informasi baru terutama tentang budayabudaya baru yang ia temui di perantauan.

Bagi peneliti berikutnya yang tertarik untuk melakukan pengembangan penelitian ini, disarankan untuk menggunakan teori gaya belajar lainnya. Hal ini dilakukan untuk memperkaya lagi hasil penelitian dan memberikan informasi gaya belajar seperti apa yang akan membantu mahasiswa perantau untuk beradaptasi dengan lingkungan baru. Selain itu, bagi mahasiswa perantau, sudah tentu bisa mengasah kembali gaya belajar yang digunakan terutama menggunakan gaya belajar Collaborative dan Independent.

\section{DAFTAR PUSTAKA}

Alreck, P. L., \& Settle, R. B. (2004).

The Survey Research Handbook. Boston: McGraw-Hill/Irwin

Azwar, S. (2012). Metode Penelitian. Yogyakarta: Pustaka Pelajar.

Bucker, J. Furrer, O., \& Lin, Y. (2015). Measuring cultural intelligence (CQ): A new test of the CQ scale. International Journal of Cross Cultural Management.

Chen, S.-H. (2015). Cultural Intelligence, Psychological Well-Being, and Employability of Taiwan's Indigenous College Students. 
Review of European Studies, 147.

Chong, O. S., \& Mahamod, Z. (2014). Gaya Pembelajaran Pelajar Bahasa Melayu Berdasarkan Gaya Pembelajaran Grasha (Student Learning Style of Malaysia).

Devinta, M. (2015). Fenomena Culture Shock (Geger Budaya) Pada Mahasiswa DPD RI. (2015, Agustus 15). Irman

Gusman: Pembangunan di Indonesia tidak merata. Retrieved from DPDRI: https://dpdri.merdeka.com/berita/ir man-gusman-pembangunan-diindonesia-tidak-merata150815o.html.

Early, P. C., \& Ang, S. (2003). Cultural Intelligence. California: Santford, University Press.

Grasha, A. F. (2002). Teaching With Stlye (A Practical Guide to Enhancing Learning By Understanding Teaching \& Learning Style). San Bernadio: Alliance Publisher.

Gunawan. A. (2004). Genius Learning Strategy petunjuk Praktis untuk Menerapkan Accelerated Learning. Jakarta: PT Gramedia Pustaka Utama

Keyvanara, M., Yarmohammadian, M. H., \& Soltani, B. (2014). The relationship between cultural intelligence and social compatibility in Isfahan University

Kurniawan, M. R. (2015). Kesesuaian Proses Perkuliahan Dengan Gaya Belajar

Li, M., Mobley, W. H., \& Kelly, A. (2013). When Do Global Leaders Learn Best to Develop Cultural An Investigation of the Moderating Role of Experiential. Academy of Management Learning \& Education, 33-42. Mahasiswa Terhadap Prestasi Belajar. Teknodika, 69.

Nugraheni, E., \& Pangaribuan, N. (2006).
Gaya Belajar dan Strategi Belajar Mahasiswa Jarak Jauh : Kasus di Universitas Terbuka. Jurnal Pendidikan Terbuka dan Jarak Jauh, 69.

Papilaya, J. O., \& Huliselan, N. (2016). Identifikasi Gaya Belajar. Jurnal Psikologi UNDIP, 57. Perantauan di Yogyakarta.

Primasari, W. (2014). Pengelolaan Kecemasan dan Ketidakpastian Diri Dalam Berkomunikasi Studi Kasus Mahasiswa Perantau. Jurnal Ilmu Komunikasi, 35.

Sugiyono. (2013). Statistik Untuk Penelitian. Bandung: Penerbit Alfabeta.

Sutherland, A., Edgar, D., Duncan, P., \& Caledonian, G. (2015). International Infusion in Practice - From Cultural Awareness to Cultural Intelligence. Journal of Perspectives in Applied Academic Practice, 34.

Syah, M. C. (2014). Pengaruh Potensi Akademik, Gaya Belajar dan Penyesuaian Diri di Perguruan Tinggi Terhadap Prestasi Akademik Mahasiswa Tahun Pertama. 36-37. Retrieved November 13, 2016

Wiyono, K., Liliasari, Setiawan, A., \& Paulus, C. (2012). Model Multimedia Interaktif Berbasis Gaya Belajar Untuk Meningkatkan Penguasaan Konsep Pendahuluan Fisika Zat Padat. Jurnal Pendidikan Fisika Indonesia, 75-76. 
